\title{
Makna Upacara Pawintenan Bagi Umat Hindu Di Desa Batu Nindan Kecamatan Basarang Kabupaten Kapuas
}

\author{
Ni Wayan Gateri \\ Institut Agama Hindu Negeri Tampung Peyang Palangka Raya \\ wayan_gateri@yahoo.co.id
}

\begin{abstract}
Pemangku as someone who leads the ceremonial process in Hinduism must be someone who has Viveka Jnana and has gone through the process of the marriage ceremony. Pemangku marriage ceremony can be divided into three types, namely Sari Pawintenan, 2) Mepedamel Pawintenan, 3) Samskara Eka Jati Pawintenan. This study aims to determine the meaning of the wedding ceremony carried out by prospective Pemangku in Batu Nindan Village, Kapuas Regency. Descriptive qualitative research methods are used in this study to solve problems. The marriage ceremony is a stage that must be passed by someone to become a Pemangku. The implementation of the marriage ceremony from generation to generation aims to legitimize someone as a Pemangku on a scale and niskala basis. The marriage ceremony also has the aim of purifying the prospective stakeholder physically and mentally so that in carrying out his duties as a Pemangku it can be carried out sincerely in accordance with the guidance of Ida Sang Hyang Widhi Wasa. A person who has gone through a stakeholder marriage ceremony is given the freedom of ayah-ayahan banjar because a Pemangku provides services to the people regardless of time. Based on research conducted in Batu Nindan Village, it was concluded that the marriage ceremony has a religious meaning, a social meaning for service to the people, and a cultural meaning.
\end{abstract}

Keywords: Meaning of Ceremony; Pawintenan; Hindus people

\begin{abstract}
Abstrak
Pemangku sebagai seseorang yang memimpin proses upacara dalam agama Hindu haruslah seseorang yang memiliki Viveka Jnana dan telah melalui proses upacara pawintenan. Upacara pewintenan Pemangku dapat dibedakan menjadi tiga jenis yaitu Pawintenan sari, 2) Pawintenan mepedamel, 3) Pawintenan Samskara Eka Jati. Penelitian ini bertujuan untuk mengetahui makna upacara pewintanan yang dilaksanakan oleh calon Pemangku di Desa Batu Nindan Kabupaten Kapuas. Metode penelitian kualitatif deskriptif digunakan dalam penelitian ini untuk memecahkan permasalahan. Upacara pewintenan merupakan tahap yang harus dilalui oleh seseorang untuk menjadi Pemangku. Pelaksanaan upacara pewintenan secara turun temurun bertujuan untuk mengesahkan seseorang sebagai Pemangku secara sekala dan niskala. Upacara pewintenan juga memiliki tujuan untuk mensucikan calon Pemangku secara lahir dan batin sehingga dalam melaksanakan tugas sebagai seorang Pemangku dapat dilaksanakan dengan ikhlas sesuai dengan tuntunan Ida Sang Hyang Widhi Wasa. Seseorang yang sudah melalui upacara pewintenan Pemangku, diberikan kebebasan ayah-ayahan banjar karena seorang Pemangku memberikan pelayanan kepada umat tanpa mengenal waktu. Berdasarkan penelitian yang dilakukan di Desa Batu Nindan diperoleh kesimpulan bahwa upacara pewintenan memiliki makna religius, makna sosial pelayanan kepada umat, dan makna budaya.
\end{abstract}

Kata Kunci: Makna Upacara; Pawintenan; Umat Hindu 


\section{Pendahuluan}

Kehidupan beragama tidak lepas dari beberapa faktor penunjang lainnya, seperti kitab suci, hari suci keagamaan, orang-orang suci, tempat suci, disamping ajarannya itu sendiri. Maka semua faktor komponen tersebut saling berkaitan dalam membina dalam kehidupan beragama sangat mutlak, Pendalaman dan penghayatan agama tidak hanya dapat dilakukan dengan mepelajari ajarannya saja, atau melaksanakan ibadahnya saja di tempat-tempat suci. diperlukan orang-orang suci, Orang-orang bijaksana untuk menuntun, membimbing, agar tidak terlalu jauh menyimpang dari hakekat ajaran agama yang diajarkan. Diperlukan orang-orang yang tahu dan punya wewenang di dalam memimpin suatu upacara. Bisa diumpamakan seperti pengendara kendaraan seharusnya sudah memiliki Surat Ijin Mengemudi (SIM) jika tidak, pasti ditindak karena melanggar peraturan lalu lintas. Seorang dokter berhak memberikan resep obat kepada orang sakit karena dokter telah memiliki ijin untuk itu. Tentu tidak mudah mendapatkan kewenangan dan ijin tersebut. Bisa didapat setelah melalui beberapa tahapan dalam proses yang berlaku. Begitu pula perlu adanya orang suci/pendeta/pinandita untuk memimpin upacara agama Hindu.

Sejalan dengan hal tersebut, kehidupan agama Hindu telah muncul keinginan umatnya untuk meningkatkan cara-cara hidup beragama serta mendalami ajaran-ajaran agamanya dengan pendekatan rasionalis, dan filosofis guna menembus dogmatis, dengan menggunakan kajian sastra agama yang terhimpun dalam berbagai pustaka, rontal, peninggalan leluhur, betapa pentingnya bentuk-bentuk upacara dan upakara agama untuk mendapat penelitian, dapat dipahami arti, fungsi dan makna, guna menambah mantapnya perasaan di dalam melaksanakan upacara itu sendiri. Khusus didalam upacara pawintenan masih terdapat berbagai variasi, baik mengenai pengertianya, upakaranya maupun mengenai tatacaranya. Adanya variasi-variasi itu memang beralasan juga karena agama Hindu bersifat fleksibel dan elastis, dalam arti dapat dilaksanakan menurut desa, kala, dan patra.

Begitu pula dengan upacara pawintenan yang dilaksanakan di luar pulau Bali, seperti di Desa Batu Nindan Kecamatan Basarang Kabupaten Kapuas, Provinsi Kalimantan Tengah juga dilaksanakan menurut desa, kala, dan patra. Tim Penyusun (1999:1) Pawintenan Pemangku/Pinandita, Wasi, Mangku Dalang, dan sejenisnya tergolong dalam tingkat Eka Jati. Walaupun bagi seorang Pinandita untuk mampu melaksanakan tugasnya juga perlu belajar berguru. Namun tingkat pengetahuan yang dipelajari tidaklah setinggi Pandita/Sulinggih. Weda yang dipelajari sangat terbatas umumnya hanya yang berhubungan dengan Pengastawa, Upacara pengesahannya jauh berbeda dengan dengan pengesahan menjadi Sulinggih. Upacara yang dilakukan untuk seorang Pinndita hanya sampai pada Pawintenan. Upcara Pawintenan boleh dilaksanakan oleh umat secara umum, yang bermaksud untuk menyucikan diri. Sebelum akan mempeljari kitab-kitab suci, sebelum bertugas menangani upacara yang agak besar dan sebagainya. Bagi mahasiswa yang baru akan masuk kuliah dalam rangka mempelajari kitab-kitab suci maka diadakan penyucian diri yang disebut upacara Pawintenan/ Upanayana (Tim Penyusun, 1999:167).

Lebih lanjut menurut Wiana (2002:292), “upacara pawintenan adalah suatu upacara pengesahan secara ritual sakral bahwa seseorang telah memiliki pengetahuan dan kemampuan yang disebut Viveka Jnana”. Dalam buku Dasar-dasar KePemangkuan menyebutkan "seperti halnya dalam upacara pawintenan Pemangku ada 3 jenis yaitu; 1) Pawintenan sari, 2) Pawintenan mepedamel, 3) Pawintenan Samskara Eka Jati. Pawintenan sari merupakan upacara pawintenan yang paling sederhana. Upacara ini hanya memohon wangsupada kehadapan Ida Sang Hyang Widhi Wasa di Pura dimana yang bersangkutan akan menjadi Pemangku. Pawintenan Sari harus disaksikan oleh krama 
dadia Pura yang bersangkutan, Pemangku yang diwinten dengan cara ini diberi nama panggilan bapa mangku, ketut mangku dan sebagainya. Dengan tetap melaksanakan kode etik seperti : berbuat dharma, sabar, jujur, berbudi luhur, santun, selalu teguh melaksanakan ajaran agama, memahami tri kona, kasih sayang, tidak mabuk-mabukan, tidak suka brjudi, berkelahi dan lainnya. Pawintenan Mepedamel dilaksanakan oleh Pinandita, yang sudah mempunyai wewenang untuk melaksanakan Ngeloka Palasraya. Pinandita juga disebut Sang Hyang Yogi Swara selaku penabean. Upacara pawintenan ini harus disaksikan oleh : PHDI Kecamatan atau Kabupaten, pemerintah setempat, perangkat desa adat, Kementrian Agama Kabupaten, Guru Rupaka dan keluarga. Pemangku yang diwinten dengan tingkatan seperti ini diberi gelar Jero Mangku, dan diberi wewenang untuk nganteb banten Dewa Yajna dan menggunakan Bajra. Pawintenan Samskara Eka Jati. Pawintenan ini merupakan pawintenan untuk meningkatkan status Pemangku dengan panggilan Jero Mangku menjadi Jero Gede selaku pinandita. Upacara pawintenan ini dilakukan oleh Pendeta/Sulinggih yang sudah mempunyai wewenang untuk melaksanakan Ngeloka Palasraya atau disebut juga Sang Yogi Swara selaku guru pengajian. Upacara Pawintenan ini harus disaksikan oleh Manggala desa/prajuru desa.

Pawintenan adalah upacara penyucian diri, yang disebut upakara Pawintenan dan agem-ageman seorang Pemangku supaya disesuaikan dengan tingkat Pura yang diamongnya sesuai dengan dalam sesananya (Tim Penyusun,1999:19). Dalam kaitannya atau hubungannya penelitian ini adalah Pemangku dari salah satu Pura yang sudah diwinten baik secara Pawintenan Sari, Mepedamel, Maupun Samskara Eka Jati yang ngayah di Desa Batu Nindan Kecamatan Basarang Kabupaten Kapuas, Povinsi Kalimantan Tengah. Pemangku artinya nampa, menyangga, atau memikul beban, atau memikul tanggung jawab. Dalam penelitian ini Pemangku memikul beban dan tanggung jawab sebagai pelayan atau perantara antara yang punya kerja dengan Ida Sang Hyang Widhi Wasa atau Ida Bhatara Kawitan. Pemangku orang yang menerima tugas pekerjaan untuk memikul beban atau tanggung jawab sebagai pelayan Ida Sang Hyang Widhi sekaligus pelayan umat Hindu atau masyarakat. Dengan tanggung jawab melaksanakan yajna di Pura Pemangku Pura mempunyai tanggung jawab yang sangat berat. Pemangku harus bertanggung jawab atas kesucian pura dan kegiatan-kegiatan lainnya yang berkaitan dengan Pura yang diemongnya. Pemangku harus menjaga kesucian dirinya, asuci laksana, selalu menjaga kebersihan dan kesucian jasmani dan rohani. Pemangku juga menjaga kelingsirannya, meskipun usianya masih muda dalam arti harus dapat memberikan contoh yang baik, menjadi panutan, berpikir yang baik, berkata yang baik, dan berbuat yang baik. (mengamalkan ajaran Tri Kaya Parisudha). Terkait dengan makna pewintenan masih sangat kurang untuk dipahami oleh umat saat ini di Desa Batu Nindan Kecamatan Basarang Kabupaten Kapuas, Provinsi Kalimantan Tengah, Oleh sebab itu, peneliti melakukan penelitian yang mengangkat permasalahan tentang bagaimanakah makna upacara Pawintenan bagi umat Hindu di desa Batu Nindan Kecamatan Basarang Kabupaten Kapuas? Dan bagaimanakah sarana dan prasarana upacara Pawintenan bagi umat Hindu di Desa Batu Nindan, Kecamatan Basarang Kabupaten Kapuas? Adapun tujuan penelitian ini untuk mengkaji secara mendalam tentang makna upacara pawintenan bagi umat Hindu yang berada di Desa Batu Nindan Kecamatan Basarang Kabupaten Kapuas. Dengan dilakukan penelitian ini diharapkan dapat memberikan wawasan terkait dengan makna upacara pawintenan pada umat Hindu di Desa Batu Nindan Kecamatan Basarang Kabupaten Kapuas.

\section{Metode}

Penelitian ini menggunakan jenis penelitian deskriptif dengan pendekatan kualitatif. Tempat penelitian berada di Desa Batu Nindan Kecamatan Basarang Kabupaten 
Kapuas, karena peneliti ingin menggali dan mengkaji secara mendalam Makna Upacara Pawintenan di desa Batu Nindan Kecamatan Basarang Kabupaten Kapuas. Desa ini yang berlokasi di Provinsi Kalimantan Tengah memiliki adat istiadat serta nilai-nilai relegi yang sangat kuat yang dapat mewarnai prilaku kehidupan beragama umat Hindu. Selain itu untuk mendapatkan perhatian dalam pembinaan umat Hindu dalam melestarikan dan mengembangkan kekayaan leluhur. Tradisi dalam agama Hindu untuk melaksanakan Upacara Pawintenan di desa Batu Nindan Kecamatan Basarang Kabupaten Kapuas, juga sangat perlu dilestarikan sampai ke masa depan. Penelitian ini pada dasarnya lebih menekankan pada pemahaman terhadap makna upacara pawintenan, sarana upacara pawintenan, dan implementasi dari upacara pawintenan. Studi agama dan budaya pada umumnya pendekatan proses, kontek, dan perspektifnya. Pemangku/Pinandita, yang bertindak dalam menangani permasalahan yang terjadi dalam interaksi kehidupan beragama dan bermasyarakat, maka dilakukan identifikasi terhadap beberapa fokus penelitian dengan didukung oleh penelitian yang telah dilakukan sebelumnya. Dalam teknik pengumpulan data menggunakan Observasi, Wawancara dan Dokumentasi.

\section{Hasil dan Pembahasan}

Sudah menjadi suatu tradisi dalam masyarakat yang beragama Hindu bahwa dalam melaksanakan upacara yajna tertentu yang besar atau kecil Umat Hindu biasanya meminta bantuan Pendeta atau Pinandita/Pemangku. Pinandita atau Pemangku akan bertindak sebagai perantara antarkan yang melaksanakan upacara yajna, dalam hal ini Pemangku sebagai peminpin upacara untuk menyelesaikan upacara (nganteb). Penggunaan Pemangku sudah menjadi tradisi, karena umat hindu sejak jaman dahulu sudah terbagi dalam kelompok-kelompok profesi, kelompok brahmana mempunyai profesi dibidang keagamaan yang paling memahami ajaran-ajaran agama termasuk tatacara beragama dan upacaranya. Pemangku sebagai nganteb upacara. Sudah menjadi tradisi juga Pemangku untuk kegiatan upacara harian dan yajna yang kecil-kecil umat Hindu biasanya laksanakan sendiri tanpa bantuan pendeta maupun Pemangku. Implementasi dari upacara pawintenan bagi umat Hindu di Desa Batu Nindan Kecamatan Basarang Kabupaten Kapuas. Dalam arti penerapan sehari-hari Pemangku sangat dibutuhkan terutama dalam nganteb upacara yajna, seperti odalan, otonan, tiga bulanan dari anak-anak mereka, potong gigi, upacara bhuta yajna dan pitra yajna.

\section{Makna Upacara Pawintenan di Desa Batu Nindan Kecamatan Basarang Kabupaten Kapuas \\ a. Makna Relegi}

Nilai-nilai atau norma-norma dipegang dan dijaga dengan penuh perhatian agar jangan sampai menyimpang dan lepas dari aturan. Kata relegare artinya mengikat, dengan maksud mengikatkan diri dengan kekuatan gaib yang suci. Kekuatan gaib yang suci itu diyakini oleh umat Hindu sebagai kekuatan yang menentukan jalan hidup dan dapat mempengaruhi kehidupan manusia. Dengan demikian kata religi itu pada dasarnya mempunyai pengertian sebagai keyakinan akan adanya kekuatan gaib, yang menentukan jalan hidup dan mempengaruhi hidup manusia, yang dihadapi secara hati-hati dan diikuti dengan jalan dan mengikuti aturan-aturan serta norma-norma agar tidak menyimpang sesuai yang telah ditetapkan oleh kekuatan gaid tersebut. Religius berasal dari kata dasar religi yaitu religion yang artinya agama (Jalaludin, 2008:25). Percaya kepada Tuhan atau kekuatan sebagai pencipta, pemelihara dan pelebur merupakan suatu eksresi dari kepercayaan hidup dansuatu keadaan jiwa,cara kita untuk mencerminkan kecintaan dan kepercayaan terhadap Tuhan Yang Maha Kuasa. Jadi dapat diartikan religius merupakan suatu sikap yang kuat dalam pemeluk agama dan menjalankan ajarannya serta sebagai 
cerminan dirinya atas ketaatannya terhadap ajaran agama yang dianutnya, religious dapat juga diartikan suatu keadaan diri seseorang dalam melaksanakan aktivitasnya selalu berkaitan dengan agamanya.

Demikian halnya Pemangku sangat perlu memahami ajaran agama Hindu karena sebagai pelayan Ida Sang Hyang Widhi Wasa dan sekaligus pelayan umat sehingga dapat mengamalkan, menghayati dengan baik dan benar. Seorang Pemangku dapat melaksanakan tugasnya dengan benar, maka Kerangka dasar agama Hindu perlu dipahami dan dihayati dengan baik.Tattwa/filsafat agama Hindu mengajarkan lima keyakinan/kepercayaan umat Hindu yang disebut dengan Panca Sradha yakni : Percaya terhadap adanya Tuhan (Widhi Tattwa), Percaya terhadap adanya atma (Atma Tatwa), Percaya terhadap Karma phala (Karma Phala Tattwa), Percaya terhadap Samsara/Punarbawa (Reinkarnasi), Percaya terhadap Moksa (mukti, kebebasan) (Suharsana, 2006:33).

Pemangku meyakini adanya Panca Sradha sangat penting dan perlu sangat baik sekali, seorang Pemangku sebagai pelayan Ida Sang Hyang Widhi Wasa berkeyakinan terhadap Tuhan dan atma. Tuhan itu tak terpikirkan, Maha Ada, Maha Kuasa. Maha Tahu, Maha Karya. Dimana-mana ada, Maha Esa, Acintya. Hanya para rsi memberi banyak nama "Ekam sat wiprah bhahuda wadanti". Dalam Mantram Trisandya bait ketiga disebutkan "Eko Narayanad nadwityo asti Kascit" artinya hanya satu Tuhan tidak ada duanya. Tuhan/Ida Sang Hyang Widhi diwujudkan sesuai dengan fungsinya sebagai Pencipta Dewa Brahma, sebagai pemelihara Dewa Wisnu, sebagai pelebur Dewa Siwa. Hal ini sangat perlu di ketahui oleh Pemangku. Seorang Pemangku harus mengetahui etika atau susila seperti, Tri Kaya Parisudha, Catur Marga, Panca Yama dan Nyama Brata, Catur Purusa Arta, Catur Paramita, Tri Hita Karana, Asta Brata. Ajaran tentang Yama dan Nyama Brata erat sekali dengan ajaran pengendalian diri. Terkait dengan hal tersebut berikut ini hasil wawancara dengan informan.

Mengenai "makna religius dikatakan oleh informan sebagai berikut : makna religious dari upacara pawintenan secara lahir bhatin perbuatan baik, secara bhatin disesuaikan dengan alam lingkugan sarwa prani, Bhatara Guru, sesuai dengan swadharma masing-masing. Pemangku harus meyakini adanya lima keyakinan umat Hindu yang disebut dengan Panca Sradha, Tri Kaya Parisudha (wawancara dengan Widana).

Berkenaan dengan upacara pawintenan seperti dikatakan oleh informan berikutnya adapun makna dari upacara pawintenan secara religius untuk menyucikan diri sendiri, orang yang mau jadi Pemangku harus diwinten terlebih dahulu, setelah diwinten baru bisa naik turun di Pura yang demongnya, pawintenannya disebut dengan Eka Jati (wawancara dengan Bagus Puja).

Senada dengan informan di atas, menurut informan Nyoman Kadra makna religius untuk membersihkan diri secara lahir dan bhathin agar dalam mempelajari ajaran kesusilaan keagamaan Hindu atau tentang keyakinan lima keyakinan umat Hindu yaitu Panca sradha, Tri Kaya Parisudha, Tri Hita Karana, dan ada tiga Pawintenan menurut mereka pawintenan Sari, Mapedamel, dan Pawintenan Samskara Eka Jati"Jero Mangku juga menyebutkan hak dari Pemangku adalah bebas dari ayah-ayahan banjar, dapat bagian seperempat sesari dari pura.dan berkewajiban nganteb di Pura yang diemongnya.

Dengan menyimak beberapa pendapat informan di atas upacara pawintenan mempunyai makna religius untuk menyucikan diri secara lahir dan bhatin Pemangku, lahir bhatin perbuatan baik, secara bhatin disesuaikan dengan alam lingkungan, dan sesuai dengan swadharma masing-masing. Pemangku harus meyakini adanya lima keyakinan umat Hindu yang disebut dengan Panca Sradha, Tri Kaya Parisudha, senada dengan pendapat mangku Bagus Puja apabila yang mau jadi Pemangku harus diwinten terlebih dahulu, setelah diwinten baru bisa naik turun di Pura yang demongnya, untuk 
membersihkan diri secara lahir dan bhathin agar dalam mempelajari ajaran kesusilaan keagamaan Hindu atau tentang keyakinan lima keyakinan umat Hindu yaitu Panca sradha, Tri Kaya Parisudha, Tri Hita Karana, maupun gegelan pemangngku dan mantra-mantra suci. Pada intinya makna dari upacara pawintenan sesuai dengan pendapat informan di atas untuk menyucikan diri secara lahir maupun bhatin. Dengan demikian orang yang sudah diwinten diibaratkan sebagai permata yang berkilauan secara lahir batinnya sudah disucikan. Sebagai pelayan Ida Sang Hyang Widhi sekaligus pelayan umat seorang Pemangku harus bertanggung jawab atas kesucian Pura yang diemongnya dan dirinya sendiri.

\section{b. Makna Sosial}

Pemangku dalam masyrakat mempunyai peran yang sangat penting dalam masyarakat terutama umat Hindu. dikarena akan setiap upacara atau yajna, sepanjang tidak menggunakan sulinggih, maka Pemangku yang diminta bantuan untuk nganteb upakara (banten), Tidak semua upacara yang diselesaikan oleh Pendeta. Pada umumnya masyarakat atau umat Hindu sudah memahami tradisi dan kebiasaan, upacara yang dipuput oleh Pendeta, dan yang bisa dihaturkan oleh Pemangku dan yang dapat dipersembahkan juga sendiri. Pemangku berfungsi sebagai perantara antara umat yang mempunyai kerja (yajna), untuk menghubungkan diri dengan Sang Hyang Widhi Wasa/Bhatara Kawitan/Leluhur. Pemangku sering disebut pelayan Ida Sang Hyang Widhi dan sebagai pelayan umat. Dalam posisi itulah maka Pemangku menduduki posisi yang sangat penting dan terhormat.

Mengingat peran penting Pemangku di masyarakat maka, seorang Pemangku diharapkan dapat menjadi panutan, memberi contoh yang baik pada umat dan menuntun, membina masyarakat dalam mendekatkan diri kepada Ida Sang Hyang Widhi Wasa. Itulah sebabnya untuk bisa menjadi Pemangku tidaklah mudah karena harus memenuhi beberapa persyaratan. Secara formal terutama yang menyangkut prosedur administrasi PHDI menetapkan syarat-syarat bagi calon Pinandita hampir sama dengan calon Sulinggih. Kecuali menyangkut dengan guru nabe. Oleh karena seorang Pinandita yang diresmikan dalam proses penyuciannya tidak memerlukan guru nabe. Dalam aspek mental spiritual seorang calon Pinandita sangat diperhatikan sikap dan prilakunya. Pinandita yang sudah diresmikan melalui upacara Pawintenan berbuat yang tidak terpuji, menyalahi aturan maka, ia wajib mengulang lagi melaksanakan upacara penyucian diri.

Lebih lanjut ada beberapa cara yang umum dalam pemilihan Pemangku sebagai berikut; 1) Melalui Nyanjan, cara ini ditempuh melalui bantuan seorang mediator yang mampu yang mampu menghubungkan diri dengan dunia gaib, kemudian menerima petunjuk-petunjuknya secara langsung, siapa yang akan dipilih untuk menjadi Pemangku di Pura tersebut. Kemudian petunjuk itu apa diterima oleh atau tidak oleh umat yang mendukungnya Pura tersebut kembali lagi pada umat itu sendiri. 2) Melalui Keturunan, cara ini tidak melalui prosedur yang berbelit-belit oleh karena cara ini telah diterima secara tradisi. Dan 3) Melalui Pemilihan, cara ini sering dilakukan bilamana cara-cara lain ternyata tidak berhasil dilaksanakan. Ada juga yang dilaksanakan secara tradisi sehingga akan berlanjut untuk waktu berikutnya, Dalam proses pemilihan penentuan syaratsyaratnya disamping yang telah ditentukan secara umum, sering masih ditambahkan dengan syarat-syarat yang ditetapkan secara khusus oleh umat yang bersangkutan (Tim Penyusun, 1999:175).

Betapapun juga tugas seorang Pemangku/rohaniawan, yang tergolong Ekajati (Pemangku) lebih-lebih yang tergolong Dwijati (Sulinggih) adalah cukup berat. Oleh karena itu pula timbal baliknya yaitu berupa perhatiannya dan penghargaan dari masyarakat umat itu sendiri juga patut diberikan sewajarnya agar rohaniawan yang 
dipercayakan dalam tugas-tugas keagamaan itu dapat melaksanakan tugasnya dengan baik sesuai dengan perasaannya dengan berperanan sebagai tokoh panutan.

Kemudian makna sosial dari upacara pawintenan hasil wawancara dari informan berikut. "Sebagai pelayan umat, saya sebagai seorang Pemangku melaksanakan tugas dengan lascarya, dengan tulus ikhlas melayani umat Hindu dengan penuh hati" (Wawancara Widana). Selanjutnya "berkenaan dengam upacara pawintenan makna Sosial Pemangku karena kewajibannya sebagai pelayan umat tidak memperhitungkan waktu walaupu seharian penuh atau dua hari siap melaksanakan tugasnya dengan tulus ikhlas" (wawancara dengan mangku Kadra) "Kita sebagai umat Hindu rasa sosial dengan umat yang melaksanakan yajna sangat tinggi” (Wawancara dengan Bagus Puja).

Dengan menyimak beberapa pendapat informan di atas maka, makna sosial dari Pemangku sangat besar dengan perasaan tulus ikhlas untuk melayani umat tanpa pamrih karena itu tugas dan kewajiban dari seorang Pemangku sebagai pelayan umat sangat lah berat. Sejalan dengan pendapat di atas pemanggu ngayah bekerja dengan penuh tanggungjawab sesuai dengan kemampuannya.

\section{c. Makna Budaya}

Dewasa ini kita sedang dihadapkan pada kondisi masyarakat dunia dan masyarakat Indonesia yang sedang mengalami perubahan menghadapi tata hubungan antar bangsa daerah yang semakin terbuka dan bebas. Hal ini mendorong perlunya perubahan tatanan kehidupan masyarakat Indonesia. Arus informasi budaya yang datang dari luar maupun dari dalam semakin meningkat dan tidak dapat dicegah sehingga apabila tidak waspada, dikawatirkan akan dapat mengancam ketahanan budaya bangsa. Oleh karena itu upaya untuk memperkuat ketahanan budaya menjadi salah satu tugas penting dalam pembangunan kebudayaan. Pada era globalisai pembangunan dan pengembangan kebudayaan banyak dukungan dari berbagai sektor. Untuk dapat mencapai keberhasilan pembangunan dalam bidang budaya perlunya dilakukan dukungan yang merupakan program pendukung yang dilakukan oleh berbagai pihak untuk ikut menentukan keberhasilan pembangunan kebudayaan seperti upacara pawintenan Pemangku.

Berikut ini hasil wawancara dengan informan terkait makna budaya dari upacara pawintenan. "Makna budaya kami sebagai pemagku pewaris budaya mengenai upakara secara turun temurun dapat diterapkan sesuai dengan desa, kala, dan patra (Wawancara dengan Mangku Widana). "Makna budaya kami tidak meninggalkan warisan leluhur dengan meyesuaikan perkembangan yang ada sesuai dengan desa, kala, dan patra" (wawancara dengan Mangku Ida Bagus Puja). "Makna Budaya Kami sebagai Pemangku mengikuti warisan budaya leluhur yang sudah ada seperti mengikuti ajarannya ibaratkan pohon dengan akarnya kita sebagai pewaris dari leluhur kita harus ingat pada akarnya atau sumbernya" (wawancara dengan Mangku Kadra). Dengan menyimak beberapa pendapat di atas, maka upacara pawintenan mempunyai makna religius, sosial, budaya. Pada intinya makna dari upacara pawintenan sesuai dengan pendapat informan di atas untuk menyucikan diri secara lahir maupun bhatin. Dengan demikian orang yang sudah diwinten diibaratkan sebagai permata yang berkilauan secara lahir batinnya sudah disucikan. Sebagai pelayan Ida Sang Hyang Widhi sekaligus pelayan umat seorang Pemangku harus bertanggung jawab atas kesucian Pura yang diamongnya.

\section{Sarana dan Prasarana Upacara Pawintenan di Desa Batu Nindan Kecamatan Basarang Kabupaten Kapuas}

Banten pokok dalam pawintenan adalan banten tataban. Kemudian banten peras dan banten byakala, sedangkan untuk nyomya bhuta kala dihaturkan segehan, banten peras tujuannya untuk memohon semoga upacara pawintenan mencapai sukses (praside). 
Dalam Lontar Yajna Prakerti debutkan "peras ngarania praside Tri Guna Sakti” artinya penggunaan banten peras itu melambangkan permohonan semoga pekerjaan upacara pawintenan yang dilakulan mencapai kesuksesan. Banten sesayut yang terbuat dari daun kelapa hijau melingkar ditata helai demi helai sehingga menjadi meiseh lambang dari upaya berjuang mencari kebahagiaan tahap demi tahap, sesayut berasal dari kata ayu artinya selamat. Sesayut artinya mencari keselamatan (Wiana, 2002:292).

Selanjutnya hasil wawancara menurut informan mangku I Nyoman Kadra terkait upacara pawintenan sebagai berikut.

Pemangku menggunakan banten Saraswati melambangkan bahwa orang yang diwinten adalah orang yang sudah memiliki pengetahuan suci dari Dewi Saraswati melalui jalan yang dibenarkan oleh ajaran agama. Banten Saraswati sebagai lambang Tuhan sebagai Dewa ilmu pengetahuan. Di samping menggunakan banten byakala, prastita, durmanggala sebagai sarana penyucian. Lebih lanjut Banten Byakawonan dipakai sebuah ayakan (sidi) kemudian di atasnya di isi jejahitan yg disebut dengan kulit sayut, kulit peras, dari daun pandan/manas yang berduri. Selanjutnya diisi nasi yang dibungkus dengan pohon pisang yg berbentuk segi tiga. Penek yang disisipi bawang jahe dan terasi mentah. Disekitarnya diisi lauk pauk, jaja, buah-buahan dan sampyan naga sari, dari daun andong, genten, biasa, dan penyeneng dari daun andong.

Lebih lanjut Mantram dari banten Byakala, Durmanggala, dan Prastita oleh Pemangku/pinandita sesuai dengan pustaka suci agama Hindu Manggala Upacara sebagai berikut ini :

\section{a. Byakala Mantram :}

Om Pekulun Sang kala kali, Puniki ta pabyakala nira. Sang jaya mana, katur ring Sang kala kali, sira ta reka pakulun, angeluarana sakueh ikang kala kecarik, kala pati, kala lara, kala karongan, kala ujar, kala pepengan, kala gringgingan, kala sepetan, kala kecangkingan, kala Brahma, kala undar - andir, mekadi sekueh ikang kalawigena, keluarana denira Bhatara siva, mekadi betara - betari, lah sama mata sang kala-kali, mundur sedulur maring ipun sang abaya kala, den ipun anutugaken tuwuh, tunggunen denira Sang Hyang Premana, ketekan sasi nadyanipun.

b. Durmengala

Om Sang kala Purwa, Sang kala sakti, Sang kala Bajra, Sang kala ngulalang, Sang Kala Petre, Sang kala Suksma, Aja sira pati papanjingan pati peperet ngi, iki tadah sajinira, penek lawan trasi, bang, bawang, jahe, anadaha sira tur lunga, Menawi kirang tadahan iki jinah satak selawe, lawe setukel, maraha sira ring pasar agung nggena tuku ring pasar agung wehan sanak rabinira sowang - sowang ajasira mewali muwah pada ewahana, pada sidi swaha. Om Mrtyun jaya rakta saraya sarwarega upadrawa, papa mrtyu sangkara, sarwa kali kalika syah wigraha ngawi pada, susupena durmanggala, papa krada winasaya sarwa wighna ya namah sawaha.

c. Prayascita

Om Prayscita kare yegi. Catur warna wicintayet. Catur wawtranca pupadyam. Ang Greng reng bya stawa samam. Om Ageni rahasia mukam mungguh bungkahing hati angeseng saluwiring dasa mala, taka geseng, geseng, geseng (Sujana, dkk, 2010: 13-14).

Berdasarkan hasil dari data di lapangan dapat dipahami bahwa pabersihan/pangresikan sebuah ceper yang berisi sisig, kekosok (dari tepung beras), Tepung tawar terbuat dari daun dap-dap, kunir, dan beras yang ditumbuk, minyak wangi, dan wija, sesari.dan sampyan payasan. Isuh-isuh sebuah ceper yang berisi telur ayam, sapu 
lidi 3 biji, serabut kelapa di jepit, ngad, base tulak, Base tulak yang ujung siripnya berlawanan, samsam, kayu tulak, kayu sisih, keplugan, padang lepas, daun alang-alang, dap-dap, amel-amel, diikat dengan benang tri datu, seet mingmang. Sorohan alit terdiri dari peras, tulung, sayut. Padma sejenis jejahitan untuk memercikkan tirta. Lis pabyakawonan adalah lis ageng/gede.

Banten prayascita digunakan untuk pengelukatan atau menghilangkan sebel/Kekotoran. Banten prayascita juga untuk barang-barang yang baru dibeli yang bernilai ekonomis misalnya membeli sepeda motor, mobil, dan lain sebagainya. Pawintenan, melaspas bangunan baru, pengulapan bagi orang yang mengalami kecelakaan. Hasil wawancara dengan Serati Banten Bu Manis sebagai berikut.

Sirawista diikatkan dikepala Pemangku yang terbuat dari daun alang-alang yang berfungsi sebagai alat penyucian diri dan memusnahkan segala pengaruh negatif. Sirawista juga lambang dari arda-candra (bulan), sedangkan kepala Pemangku sebagai lambang Windu (matahari) dan bunga yang dipakai pada simpul Sirawista sebagai lambang nada (bintang), bunga pucuk kembang sepatu lambang dari Dewa Brahma, Ketiga matahari, bulan dan bintang merupakan lambang alam semesta sebagai stana Ida Sang Hyang Widhi Wasa. Sebagai upesaksi atau sebagai saksi dalam upacara pawintenan adalah banten peras, Banten Ajuman, Banten Daksina, Banten Saraswati, dan sebuah cakepan (buku). Di depan Sanggar pesaksi banten pawintenan, serta perlengkapan/ tataban, untuk yang akan mawinten tiap orang menghadapi Banten Peras 1 tanding, Byakala, dan Segehan untuk Bhuta kala. Alat Rerajahan perlengkapan untuk ngerajah adalah lekesan dengan ujungnya diisi dengan tunjung biru, pinang 25 buah. Lekesan 25 buah, ini dipakai sebagai labaan. Kemudian lekesan yang sama lagi 3 biji berisi tulisan Tri Aksara (Ang, Ung, Mang). Sirih ini akan ditelan. Lain dari pada itu madu satu takir, dan tangkai sirih sebayak orang yang diwinten sebagai kuasnya ini dipakai untuk ngerajah. Batang sirih adalah kekuatan Dewa Wisnu. Madu adalah lambang dari air kehidupan yang dicari oleh setiap mahluk. Tujuan ngerajah dalam pawintenan untuk mendapatkan perlindungan Tuhan dalam menegakkan kehidupan yang mulia di dunia ini.

Kata peras dapat diartikan sah atau resmi seperti upacara pawintenan yang dimaksud dengan sesajen peras untuk mengesahkan Pemangku yang sudah diwinten, dan bila suatu kumpulan sesajen tidak dilengkapi dengan peras, akan dikatakan penyelenggara upacaranya ten preside yang artinya tidak sah. oleh karena itu banten peras selalu menyertai sesajen-sesajen yang lain terutama yang mempunyai tujuan tertentu. Ajuman, disebut juga soda dipergunakan sendiri sebagai persembahan maupun melengkapi daksina, suci dan lain-lainnya. bila ditujukan pada leluhur salah satu peneknya diisi kunir, atau dibuat dari nasi kuning, disebut ajuman putih -kuning, dengan canang pesucian, burat wangi, dan sampyan kepet-kepet lauknya sejumlah sate dan urab-uraban. Banten Dapetan, Kelanan, Pengambean, Pabersihan, Ayaban dengan bebek guling, Bebayuhan, sesuai dengan desa kala patra dengan ulam ayam putih.

Dari data hasil wawancara informan di atas maka sarana dan prasara upacara pawintenan antara lain: banten Saraswati, Tataban, Alat ngerajah. Sirawista, Pengulapan, Pengambean, Pabersihan, Durmanggala, Ayaban Tumpeng Solas, Sesayut, Upasaksi, Suci, Pejati, Bebayuhan, Ayaban dengan bebek guling, adapun pelaksanaannya ada di Pura yang diemongnya atau di merajan masing-masing yang diwinten.

\section{Kesimpulan}

Berdasarkan uraian yang dikemukakan pembahasan sebelumnya, dapat diabstraksikan hasil analisis penelitian ini sebagai berikut. Upacara pawintenan memiliki beberapa makna, antara lain. Makna religius untuk membersihkan diri secara lahir dan bhatin agar dalam mempelajari ajaran kesusilaan keagamaan Hindu atau tentang 
keyakinan lima keyakinan umat Hindu yaitu Panca sradha, Tri Kaya Parisudha, Tri Hita Karana, dan ada tiga Pawintenan menurut mereka pawintenan Sari, Mapedamel, dan Pawintenan Samskara Eka Jati. Kemudian makna sosial dari upacara pawintenan adalah sebagai pelayan umat, sebagai seorang Pemangku melaksanakan tugas dengan lascarya, dengan tulus ikhlas melayani umat Hindu dengan penuh hati. berkenaan dengam upacara pawintenan makna Sosial Pemangku karena kewajibannya sebagai pelayan umat tidak memperhitungkan waktu walaupun seharian penuh atau dua hari siap melaksanakan tugasnya dengan tulus ikhlas. Kita sebagai umat Hindu rasa sosial dengan umat yang melaksanakan yajna sangat tinggi. Terkait dengan makna budaya, Pemangku sebagai pewaris budaya mengenai upacara dan upakara secara turun temurun dapat diterapkan sesuai dengan desa, kala, dan patra. Pemangku tidak dapat meninggalkan warisan budaya leluhurnya dengan meyesuaikan perkenbangan yang ada sesuai dengan desa, kala dan patra. Makna Budaya sebagai Pemangku mengikuti warisan budaya leluhur yang sudah ada seperti mengikuti ajarannya ibaratkan pohon dengan akarnya kita sebagai pewaris dari leluhur kita harus ingat pada akarnya atau sumbernya. Lebih lanjut simpulan terkait sarana dan prasarana upacara pawintenan antara lain: banten Saraswati, Tataban, Alat ngerajah. Sirawista, Pengulapan, Pengambean, Pabersihan, Durmanggala, Ayaban Tumpeng Solas, Sesayut, Upasaksi, Suci, Pejati, Bebayuhan, Ayaban dengan bebek guling. Harapannya kepada umat Hindu khususnya yang berada di luar Bali (baca: Kalimantan Tengah) agar upacara pawintenan tetap dilaksanakan secara berkesinambungan agar umat Hindu tetap mengetahui makna dari upacara pawintenan serta Pemangku dapat meningkatkan spiritualnya dan kesucian bhatinnya dalam rangka sebagai pelayan umat Hindu.

\section{Daftar Pustaka}

Putra, Mas. 2007. Upakara yajna. Pengadaan Buku agama Hindu dan Silabus Tentang Pasraman : Propinsi Bali.

Sudarsana, I Putu. 2001. Makna Upacara Bhuta Yajna. Denpasar: Yayasan Dharma Acarya.

Suhardana. 2006. Dasar-dasar KePemangkuan (Suatu Pengantar Dan Bahan Kajian Bagi Generasi Mendatang). Surabaya: Paramita.

Suhardana. K.M.2008. Dasar-Dasar Kesulinggihan (Suatu Pengantar Bagi Sisya Calon Sulinggih). Surabaya: Paramita.

Sujana,dkk. 2010. Manggala Upacara. Denpasar: Widya Dharma.

Tim Penyusun. 1991. Indik KePemangkuan. Proyek Peningkatan Sarana dan Prasarana kehidupan beragama tersebar di 9 Kabupaten Kota Propinsi Bali.

Tim Penyusun. 1994. Wrehaspati Tattwa, Ganapati Tattwa, Tattwa Jnana. (Kajian Teks Dan Terjemahannya. UPD Kantor Dokumentasi Kebudayaan Bali Propinsi Bali: Denpasar.

Titib, I Made. 2003. Theologi dan Simbol-simbol Dalam Agama Hindu. Surabaya: Paramita.

Wiana, I Ketut. 2002. Makna Upacara Yajna Dalam Agama Hindu. Surabaya: Paramita. 